\title{
Risk of diarrhea in patients with type 2 diabetes mellitus treated with sitagliptin: a meta-analysis of 30 randomized clinical trials
}

This article was published in the following Dove Press journal:

Drug Design, Development and Therapy

II November 2014

Number of times this article has been viewed

\author{
Qingwei Zhao' \\ Dongsheng Hong' \\ Dongsheng Zheng' \\ Yao Xiao ${ }^{2}$ \\ Baohua $\mathrm{Wu}^{\prime}$ \\ 'Department of Pharmacy, First \\ Affiliated Hospital of College \\ of Medicine, Zhejiang University, \\ Hangzhou, People's Republic of China; \\ ${ }^{2}$ College of Pharmaceutical Science, \\ Zhejiang Chinese Medical University, \\ Hangzhou, People's Republic of China
}

Correspondence: Baohua Wu Department of Pharmacy, First Affiliated Hospital of College of Medicine, Zhejiang University, 79 Qingchun Road, Hangzhou 310003, People's Republic of China

$\mathrm{Tel} / \mathrm{Fax}+86$ 57/ 87236533

Email hdswell@zju.edu.cn
Background: Sitagliptin is an important drug used for diabetes treatment and is used as a monotherapy in diabetic patients. However, there are also reported cases of diarrhea with sitagliptin use. Unfortunately, data concerning the relationship of diarrhea with sitagliptin use in various conditions have yet to be identified. Therefore, the overall incidence and risk of diarrhea with sitagliptin use have not been well defined.

Methods: We conducted searches on Embase, PubMed, and the Cochrane Library databases for relevant randomized controlled trials. Registered relevant trials at the clinical trials registration website were also searched. Statistical analyses were conducted to calculate the overall incidence, odds ratios, and $95 \%$ confidence intervals (CI) by using either random-effects or fixed-effect models according to the heterogeneity of the included studies.

Results: A total of 8,891 subjects with diabetes from 30 randomized clinical trials were included in the meta-analysis. The overall incidence of sitagliptin-associated diarrhea was $4.48 \%$ (95\% CI: $3.59 \%-5.58 \%$ ). Compared with the controls, the use of sitagliptin was not associated with a significantly increased risk of diarrhea with an odds ratio of 1.10 (95\% CI: $0.78 \%-1.55 \%$; $P=0.58$ ). No evidence of publication bias was observed.

Conclusion: Our study has shown that there is no difference in diarrhea risk between sitagliptin and controlled therapies. Moreover, sitagliptin is not a medicine that potentially increases the risk of diabetic diarrhea. More studies are recommended to further investigate this association.

Keywords: dipeptidyl peptidase-4 inhibitors, adverse reaction, odds ratio, incidence, subgroup analysis, data analysis

\section{Introduction}

Diabetes mellitus (DM) is one of the most prevalent worldwide endocrine system diseases. According to a report by Wild et $\mathrm{al}^{1}$ there were 171 million patients diagnosed with DM worldwide in the year 2000, and this number is predicted to increase to 366 million by the year 2030. Characteristics of DM include hyperglycemia and disturbances in carbohydrate levels and, typically, there is also insulin deficiency and insulin resistance. ${ }^{2}$ In clinical practice, type 2 diabetes mellitus (T2DM) is more common, ${ }^{3}$ and the main monitoring indices of T2DM are glycosylated hemoglobin $\left(\mathrm{HbA}_{1 \mathrm{c}}\right)$ levels and fasting blood glucose $(\mathrm{FBG})$ levels. ${ }^{4}$ Thus, the main strategy for T2DM therapy is to control the levels of $\mathrm{HbA}_{1 \mathrm{c}}$ and FBG. At present, oral hypoglycemic agents (OHAs) are the most commonly used treatment for T2DM. Some of these OHAs include sulfonylurea, the biguanide class of drugs, dipeptidyl peptidase-4 (DPP-4) inhibitors, and glucagon-like peptide-1 (GLP-1) agonists. ${ }^{5}$

Sitagliptin is an important OHA used for T2DM. It was the first DPP-4 inhibitor to be used in clinical practice in $2006 .{ }^{6} \mathrm{DPP}-4$ is an enzyme located in the endothelium and 
has a high affinity toward GLP-1 as a substrate. ${ }^{7}$ Sitagliptin is a highly selective DPP-4 inhibitor that can increase concentrations of intact plasma GLP-1 and lower or normalize blood glucose levels in T2DM patients. ${ }^{8}$

In monotherapy of T2DM patients, sitagliptin improved $\mathrm{HbA}_{1 \mathrm{c}}, \mathrm{FBG}$, and postprandial glucose with doses of $100 \mathrm{mg}$ and $200 \mathrm{mg}$ once daily. ${ }^{9} \mathrm{FBG}$ was dose-dependently reduced by $17.1 \mathrm{mg} / \mathrm{dL}(100 \mathrm{mg})$ and $21.3 \mathrm{mg} / \mathrm{dL}(200 \mathrm{mg}) ; \mathrm{HbA}_{1 \mathrm{c}}$ was also reduced by $0.79 \%$ and $0.94 \%$, respectively. In another monotherapy study, ${ }^{10}$ sitagliptin also improved glycemic parameters, including $\mathrm{HbA}_{1 \mathrm{c}}$ and $\mathrm{FBG}$. There are also reports of diarrhea with sitagliptin as monotherapy..$^{9,11}$ However, data concerning diarrhea with sitagliptin use in different clinical trials have not been evaluated, and the overall incidence and risk of diarrhea with sitagliptin use have not been well defined. As diarrhea could lead to a discontinuation of sitagliptin use and could be fatal in many instances, it is important to fully recognize the risk of diarrhea induced by sitagliptin. Therefore, we conducted this systematic review and meta-analysis to investigate the incidence and risk of diarrhea in T2DM patients treated with sitagliptin.

\section{Methods}

\section{Search strategy and study selection}

We searched Embase from the dates of 1974 through 2014, PubMed from 1967 through 2014, and the Cochrane Library electronic databases. Specifically, we used the following search terms treated as Medical Subject Headings (MeSH) terms or free text: "diabetes", "diabetes mellitus", "type 2 diabetes", or "noninsulin-dependent diabetes mellitus"; "sitagliptin"; and "randomized controlled trials", "clinical trials", "controlled clinical trials", "clinical trial as topic", or "randomized controlled trial as topic". Additionally, we searched the clinical trial registration website (ClinicalTrials.gov) to obtain information on the registered clinical trials. Detailed search strategies are shown in Figures S1-S3. Clinical trials that reported the occurrence of diarrhea with sitagliptin use in adult T2DM patients were eligible for inclusion.

Other inclusion criteria included: 1) the diagnosis of T2DM based on either the American Diabetes Association criteria ${ }^{12}$ or the World Health Organization criteria, ${ }^{13} 2$ ) patients who were assigned to treatment with sitagliptin, and 3) treatment with sitagliptin for a minimum duration of 12 weeks. This duration was chosen based on the fact that a study of this duration could provide relevant information on diarrhea.

\section{Data extraction and quality assessment}

Data extraction was conducted by two independent investigators (ZQW and HDS), and studies were retrieved for further consideration if judged pertinent by one or two reviewers. Discrepancies were identified and resolved by consensus or, as needed, by a third investigator (WBH) and confirmed by consensus. When there were multiple reports from the same trial, the most complete and/or most recently reported data were chosen.

For each study, the following information was extracted: first author's name, year of publication, the Clinical Trials Registry number (No NCT), treatment arm, treatment duration, mean age, number of patients in the treatment and control groups, adverse outcomes (diarrhea), change from baseline of $\mathrm{HbA}_{1 \mathrm{c}}$ and $\mathrm{FBG}$ in treatment and control groups, and dosage of sitagliptin. All of the randomized controlled trials (RCTs) included in this review had their quality assessed using the Jadad criteria. ${ }^{14}$ Scores ranged from 0 to 5 , with a high score indicating a high-quality study.

\section{Data analysis}

The number of patients with diarrhea in the sitagliptin group and the total number of patients receiving sitagliptin were extracted from the selected trials to calculate the incidence of diarrhea. For each study, the proportion of patients with diarrhea and the $95 \%$ confidence interval (CI) were derived. The odds ratio (OR) of diarrhea was calculated only with those assigned to the control group in the same trial. We used the Peto method to calculate the OR and the $95 \%$ CI because this method provides the best $\mathrm{CI}$ coverage and it was more powerful and relatively less biased when dealing with low event rates. ${ }^{15}$ Heterogeneity was assessed by using the $Q$ statistic and $I^{2}$ tests among trials. ${ }^{16}$ Heterogeneity was considered statistically significant when $P_{\text {heterogeneity }}<0.1$ or $I^{2}>40 \%$. If heterogeneity existed, the data were analyzed using a randomeffects model; if heterogeneity did not exist, a fixed-effects model was used. A statistical test with a $P$-value $<0.05$ was considered significant. The presence of publication bias was evaluated by using the Begg's and Egger's tests. ${ }^{11,17}$

All data analyses were performed by using Stata software, version 12.0 (Stata Corporation, College Station, TX, USA) and R software, version 3.0.3 (The R foundation for statistical computing, http://www.r-project.org). ${ }^{18}$

\section{Results}

\section{Search results}

A total of 1,761 articles and 94 clinical trials were identified initially through our search. After reviewing each study, 1,728 studies were excluded (Figure 1). The remaining 30 studies, with 8,891 subjects, which met our inclusion criteria, were included in our analyses. The basic characteristics of the trials included in the meta-analysis are summarized in Table 1 . The quality of the 30 clinical trials was high. 


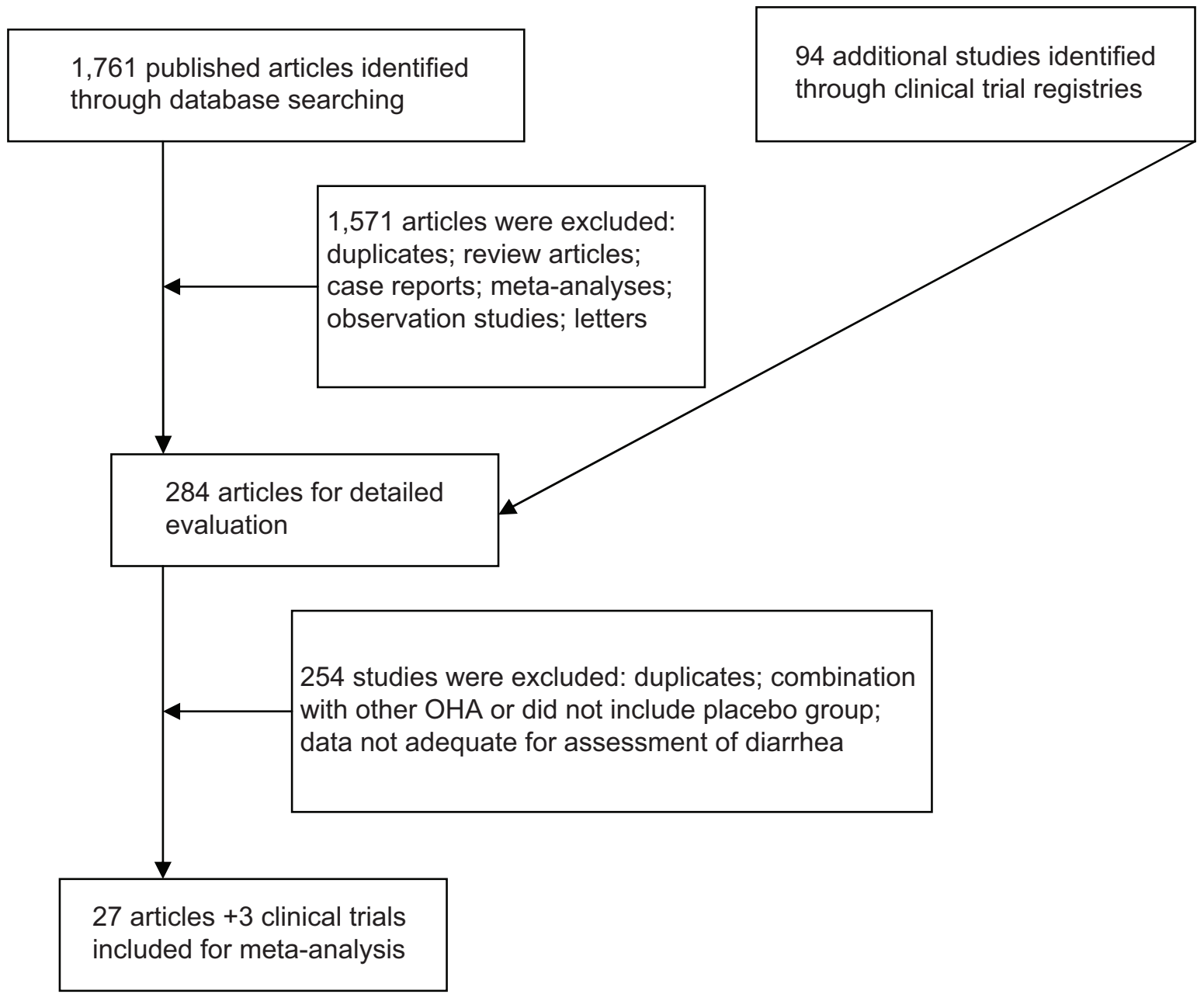

Figure I Flow chart demonstrating the process of study selection. Abbreviation: OHA, oral hypoglycemic agent.

Seven of them had Jadad scores of 5, ${ }^{19-25}$ which described the methods of randomization and blinding appropriately and provided the number of patients who withdrew and dropped from the trials. Thirteen clinical trials had Jadad scores of 4. ${ }^{910,26-36}$ This lower score was due to the fact that the researchers did not describe the methods of randomization or blinding appropriately. Ten studies had Jadad scores of 3, which included seven articles ${ }^{37-43}$ and three clinical trials from the clinical trial registration website. We performed this meta-analysis in accordance with the guidelines of the Preferred Reporting Items for Systematic Reviews and MetaAnalyses (PRISMA) Statement ${ }^{44}$ (Table S1).

\section{Incidence of diarrhea and subgroup analysis}

A total of 5,362 patients who were treated with sitagliptin monotherapy were available for analysis. The incidence of diarrhea ranged from $0 \%$ to $10.8 \%$, and the highest incidence occurred in the trials of patients treated with $50 \mathrm{mg}$ of sitagliptin once daily during a 54 -week period. ${ }^{20}$ No events of diarrhea were reported in the two trials. ${ }^{39,40}$ Based on data from 5,362 patients, the overall incidence of diarrhea was $4.48 \%$ (95\% CI: $3.59 \%-5.58 \%$; Figure 2) according to the random-effects model.

The incidence of diarrhea might be different due to the duration and dosage of sitagliptin treatment; therefore, we performed a subgroup analysis according to the duration and dosage of sitagliptin administration. If the dosage of sitagliptin was $\geq 100 \mathrm{mg}$, the incidence of diarrhea for treatment times $<30$ weeks $(3.83 \%$, 95\% CI: 3.02\%-4.84\%; Figure 3) was lower than that for treatment times $>30$ weeks (5.41\%, 95\% CI: $3.62 \%-8.01 \%$; Figure 3). However, if the dosage of sitagliptin was $<100 \mathrm{mg}$, the incidence of diarrhea did not significantly vary between groups with treatment times $<30$ weeks $(4.81 \%$, 95\% CI: $1.68 \%-12.97 \%$; Figure 3$)$ and treatment times $>30$ weeks $(4.83 \%, 95 \%$ CI: $2.83 \%-8.15 \%$; Figure 3 ). Through our subgroup analysis, our results suggest that under the conditions of high sitagliptin dosage ( $\geq 100 \mathrm{mg}$ ), a long treatment time ( $>30$ weeks) might 


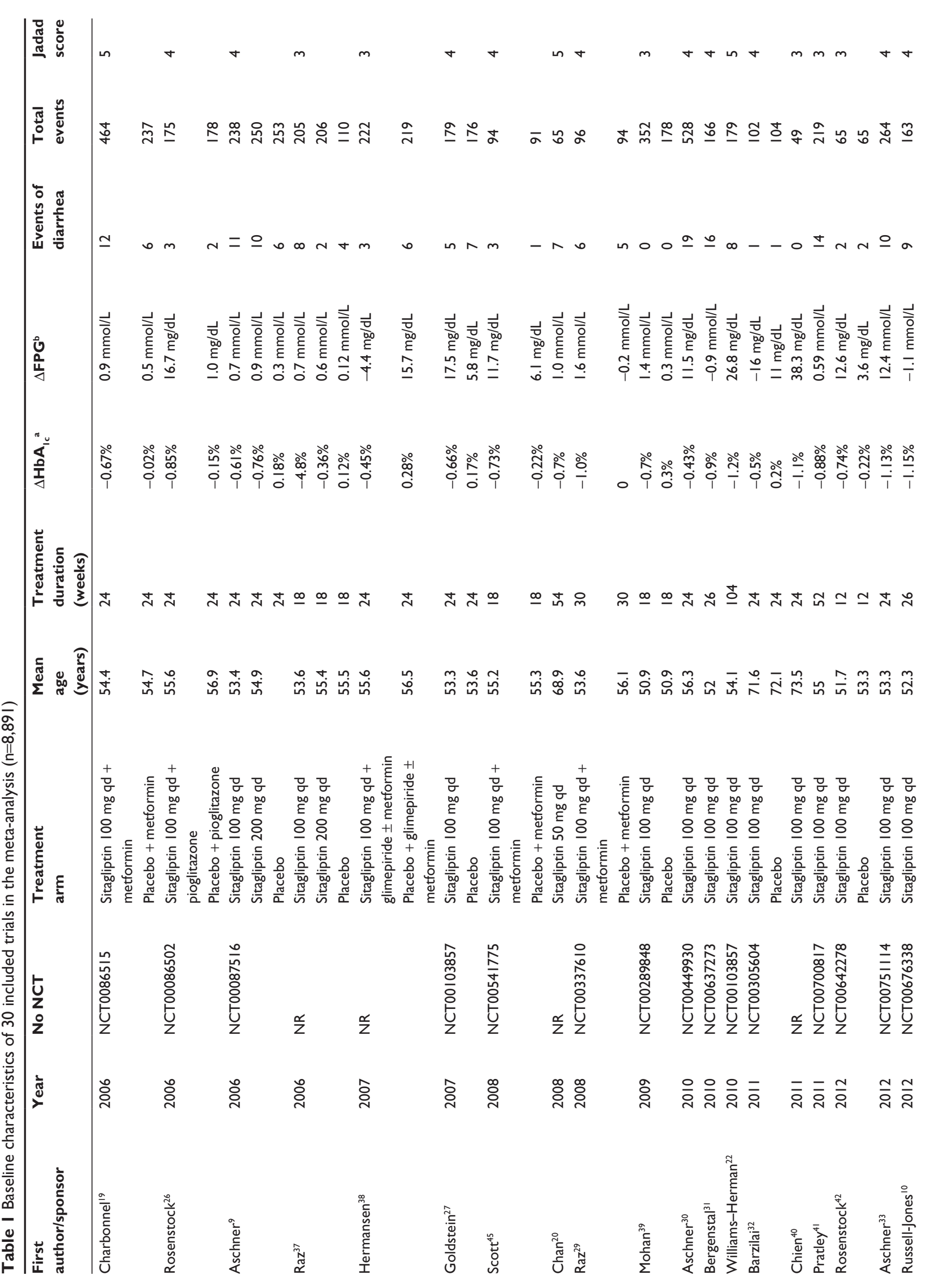




\begin{tabular}{|c|c|c|c|c|c|c|c|c|}
\hline Ln & $\nabla$ & in & & $m m$ & & $m$ & $\nabla m$ & in in $\forall$ \\
\hline$\Phi$ & $\bar{\sigma}$ & 호 & $\alpha$ & ํํ ฏి & בి & $\underline{\underline{0}}$ & ఫt & $\stackrel{\infty}{\stackrel{m}{m}: ~ ㅇ ㅣ ㄹ ~}$ \\
\hline 으 & $\forall$ & $-\infty$ & in & $N \mathrm{~m}$ & 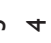 & $\sigma$ & $N-$ & $\stackrel{\sim}{\sim} \dddot{\nu}=$ \\
\hline 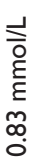 & 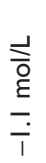 & $\begin{array}{l}\text { है } \\
\text { है } \\
\text { है }\end{array}$ & $\begin{array}{l}\stackrel{+}{\circ} \\
\stackrel{0}{\xi} \\
\xi \\
0 \\
0\end{array}$ & 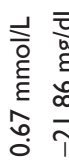 & 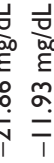 & 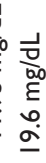 & 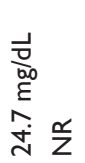 & 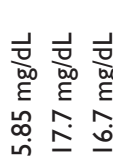 \\
\hline
\end{tabular}

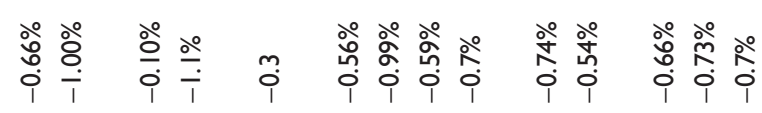

年㐫

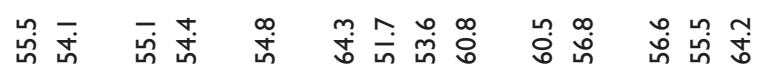

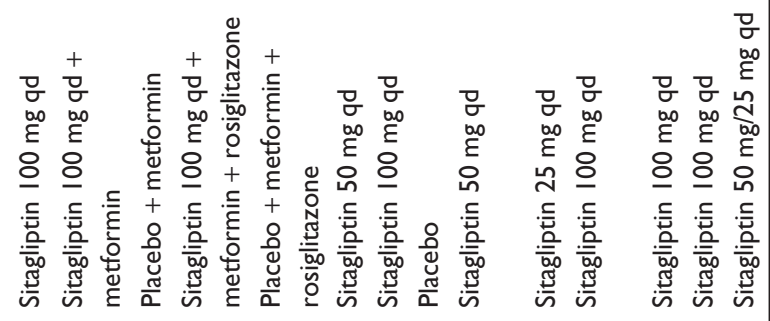

\begin{tabular}{|c|c|c|c|c|c|}
\hline 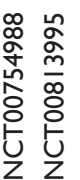 & 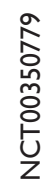 & 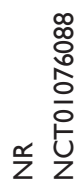 & 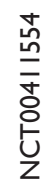 & 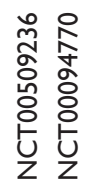 & 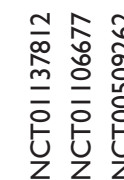 \\
\hline$\overline{0}$ & $\frac{m}{i}$ & $\frac{\nabla}{\partial} \frac{m}{\delta}$ & $\frac{\pi}{2}$ & $\frac{m}{\delta}$ 응 & $\frac{m}{\bar{c}} \frac{m}{\bar{d}}$ \\
\hline
\end{tabular}

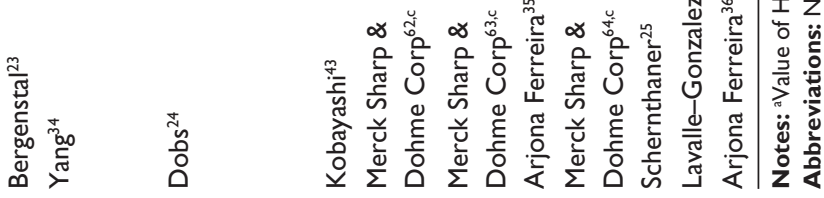

increase the incidence of diarrhea, but low sitagliptin dosages $(<100 \mathrm{mg})$ showed no significant variation between the groups of different treatment times.

\section{ORs of diarrhea}

To investigate the specific contribution of sitagliptin to the incidence of diarrhea and exclude the influence of confounding factors such as food, the disease itself, and the history of other therapeutic interventions, we determined the ORs of diarrhea between sitagliptin and placebo groups. ${ }^{9,19,24,26,27,29,32,33,37-39,42,45}$ The pooled ORs of diarrhea showed that there were no differences in diarrhea risk between treatments with sitagliptin and placebo with an OR of 1.10 (95\% CI: $0.78-1.55 ; P=0.58$; Figure 4), according to a fixed-effects model $\left(I^{2}=0 \%\right.$, $P_{\text {heterogeneity }}=0.8081$ ).

\section{Publication bias}

We observed no significant evidence of publication bias for the OR of diarrhea events in this analysis by a funnel plot (Figure 5), Egger's test $(P=0.991>0.05$, 95\% CI: -1.64 , 1.62), or Begg's test $(Z=0<1.96, P=1.0>0.05)$.

\section{Discussion}

Diarrhea associated with sitagliptin is an important issue in patients receiving medication. However, due to the high background incidence of diarrhea, it may be very difficult to distinguish between spontaneous and actual drug-related diarrhea events in T2DM patients. Wu et $\mathrm{al}^{46}$ found that, compared with controls, DPP-4 inhibitor monotherapy, which included sitagliptin, was associated with a lower risk of gastrointestinal (GI) adverse events involving diarrhea (relative risk $=0.63,95 \% \mathrm{CI}$ : [0.55-0.70], $P<0.00001$ ). So far, no studies have explored the association between diarrhea and sitagliptin. Therefore, we have conducted this study to determine the overall incidence and risk of diarrhea in T2DM patients treated with sitagliptin.

Sitagliptin as a novel T2DM therapy improves alpha islet function due to the increased concentrations of active GLP-1, which stimulates insulin secretion and inhibits glucagon secretion. ${ }^{47}$ In one study, ${ }^{48}$ sitagliptin (100 mg) reduced $\mathrm{HbA}_{1 \mathrm{c}}$ by $0.6 \%$ from a baseline of $7.7 \%$ in 555 subjects. Another study, ${ }^{49}$ comprising 743 subjects, reported that sitagliptin reduced $\mathrm{HbA}_{1 \mathrm{c}}$ by $0.8 \%$ from a baseline of $7.8 \%$. The improved hyperglycemia during sitagliptin monotherapy was sustained over at least 2 years, as shown in a 52-week study of an open-label extension. ${ }^{21}$ Sitagliptin at $100 \mathrm{mg}$ reduced $\mathrm{HbA}_{1 \mathrm{c}}$ by $0.7 \%$ from a baseline of $7.5 \%$. 


\begin{tabular}{|c|c|c|c|c|c|c|}
\hline Study & Events & Total & Proportion and $95 \% \mathrm{Cl}$ & Proportion $^{a}$ & $95 \% \mathrm{Cl}$ & W (random) \\
\hline Mohan $^{39}$ & 0 & 352 & $\leftarrow$ & 0.0000 & $0.0000-0.0104$ & $0.6 \%$ \\
\hline Schernthaner ${ }^{25}$ & 26 & 378 & 1 & 0.0688 & $0.0454-0.0992$ & $6.6 \%$ \\
\hline Russell-Jones $^{10}$ & 9 & 163 & 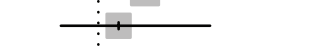 & 0.0552 & $0.0256-0.1022$ & $4.9 \%$ \\
\hline Rosenstock ${ }^{42}$ & 2 & 65 & $\begin{array}{c}: \\
\end{array}$ & 0.0308 & $0.0037-0.1068$ & $2.4 \%$ \\
\hline Bergenstal $^{23}$ & 10 & 184 & 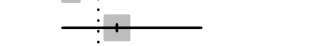 & 0.0543 & $0.0264-0.0977$ & $5.1 \%$ \\
\hline Pratley ${ }^{41}$ & 14 & 219 & $\div$ & 0.0639 & $0.0354-0.1049$ & $5.7 \%$ \\
\hline Aschner $^{33}$ & 10 & 264 & $+\vdots$ & 0.0379 & $0.0183-0.0686$ & $5.2 \%$ \\
\hline Aschner $^{9}$ & 10 & 250 & 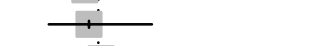 & 0.0400 & $0.0193-0.0723$ & $5.2 \%$ \\
\hline Aschner $^{9}$ & 11 & 238 & $\vdots$ & 0.0462 & $0.0233-0.0812$ & $5.3 \%$ \\
\hline Aschner ${ }^{30}$ & 19 & 528 & $\div$ & 0.0360 & $0.0218-0.0556$ & $6.2 \%$ \\
\hline Barzilai $^{32}$ & 1 & 102 & $+\quad:$ & 0.0098 & $0.0002-0.0534$ & $1.6 \%$ \\
\hline Chien $^{40}$ & 0 & 49 & 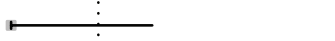 & 0.0000 & $0.0000-0.0725$ & $0.6 \%$ \\
\hline Merck Sharp \& Dohme Corp ${ }^{62}$ & 3 & 120 & $\rightarrow \quad \vdots$ & 0.0250 & $0.0052-0.0713$ & $3.0 \%$ \\
\hline Merck Sharp \& Dohme Corp ${ }^{64}$ & 1 & 588 & $\leftarrow$ & 0.0017 & $0.0000-0.0094$ & $1.7 \%$ \\
\hline Merck Sharp \& Dohme Corp 63 & 4 & 163 & $+\quad \vdots$ & 0.0245 & $0.0067-0.0616$ & $3.5 \%$ \\
\hline Lavalle-Gonzalez ${ }^{61}$ & 23 & 366 & $\vdots$ & 0.0628 & $0.0402-0.0928$ & $6.4 \%$ \\
\hline Kobayashit ${ }^{43}$ & 2 & 59 & $+\vdots$ & 0.0339 & $0.0041-0.1171$ & $2.4 \%$ \\
\hline $\operatorname{Raz}^{37}$ & 2 & 206 & $\mp \vdots$ & 0.0097 & $0.0012-0.0346$ & $2.4 \%$ \\
\hline $\operatorname{Raz}^{37}$ & 8 & 205 & 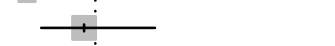 & 0.0390 & $0.0170-0.0754$ & $4.7 \%$ \\
\hline Williams-Herman ${ }^{22}$ & 8 & 179 & 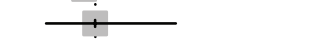 & 0.0447 & $0.0195-0.0862$ & $4.7 \%$ \\
\hline Chan $^{20}$ & 7 & 65 & + & 0.1077 & $0.0444-0.2094$ & $4.3 \%$ \\
\hline Bergenstal ${ }^{31}$ & 16 & 166 & 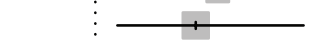 & 0.0964 & $0.0561-0.1518$ & $5.8 \%$ \\
\hline Goldstein $^{27}$ & 5 & 179 & $+\vdots$ & 0.0279 & $0.0091-0.0640$ & $3.9 \%$ \\
\hline Ajona Ferreira ${ }^{35}$ & 2 & 64 & $+:$ & 0.0312 & $0.0038-0.1084$ & $2.4 \%$ \\
\hline Ajona Ferreira ${ }^{36}$ & 11 & 210 & 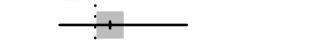 & 0.0524 & $0.0264-0.0918$ & $5.3 \%$ \\
\hline Random effects model & & 5,362 & $\dot{\phi}$ & 0.0448 & $0.0359-0.0558$ & $100 \%$ \\
\hline Heterogeneity: $l^{2}=57.6 \%, \tau^{2}=0.1708, P=0.0002$ & & & & & & \\
\hline & & & 0.15 & 2 & & \\
\hline
\end{tabular}

Figure 2 Incidence of diarrhea associated with sitagliptin.

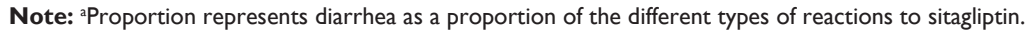

Abbreviations: $\mathrm{Cl}$, confidence interval; $\mathrm{W}$, weight.

A placebo-controlled, multicenter study ${ }^{37}$ showed that sitagliptin at $100 \mathrm{mg}$ or $200 \mathrm{mg}$ once daily reduced $\mathrm{HbA}_{1 \mathrm{c}}$ by $0.6 \%$ and $0.5 \%$, respectively, from a baseline of $8.1 \%$. All of these studies have shown that sitagliptin has a positive clinical effect in reducing glycemia as a monotherapy. However, the etiology and pathophysiology of sitagliptinrelated diarrhea are largely unknown.

In our study, we strictly defined inclusion criteria to collect the RCTs of T2DM patients treated with sitagliptin. This method of meta-analysis could increase clinical samples and improve productivity based on statistics, and we were able to obtain a more accurate conclusion to choose a suitable therapeutic scheme in clinical practice.

In our study, 8,891 patients from 30 RCTs demonstrated that the pooled incidence of sitagliptin-associated diarrhea was 4.48\% (95\% CI: 3.59\%-5.58\%). According to a subgroup analysis, we found that the incidence of diarrhea was related to the duration and dosage of sitagliptin treatment. If the dosage of sitagliptin was $\geq 100$ $\mathrm{mg}$, the incidence of diarrhea with treatment times $<30$ weeks $(3.83 \%, 95 \%$ CI: $3.02 \%-4.84 \%)$ was lower than that with treatment times $>30$ weeks $(5.41 \%, 95 \% \mathrm{CI}$ : $3.62 \%-8.01 \%$ ).

Of note, we also found no differences in diarrhea risk between sitagliptin and placebo therapies $(\mathrm{OR}=1.10,95 \% \mathrm{CI}$ : $0.78-1.55, P=0.58$; Figure 4). Sitagliptin did not increase the risk of diarrhea in patients with T2DM. One possible explanation for this finding is that diarrhea is due to the T2DM itself. As we know, GI disorders are a common complication of T2DM, including abdominal distension, diarrhea, and constipation. One study ${ }^{50}$ reports that the frequency of diarrhea is $5.3 \%$ in T2DM patients. Moreover, a large population survey asking participants about GI-related disorders ${ }^{51}$ indicated that the OR was 2.06 in diabetic patients compared with controls, and the prevalence of diarrhea was $15.6 \%$. Histological evidence of sympathetic and parasympathetic nerve impairment has been observed in T2DM patients. ${ }^{52}$ Sympathetic and parasympathetic nerves regulate the movement of the small intestine, and the damaged nerve tracts could impair GI motility. Previous studies have shown similar results with sympathetic nerve selective deletion in the islets of diabetic rats. ${ }^{53}$ Based on the autonomic nerve changes in T2DM, the 


\begin{tabular}{|c|c|c|c|c|c|c|}
\hline Study & Events & Total & Proportion and $95 \% \mathrm{Cl}$ & \multicolumn{2}{|c|}{ Proportion ${ }^{\mathrm{a}} 95 \% \mathrm{Cl}$} & $\mathbf{W}(\mathrm{ra}$ \\
\hline 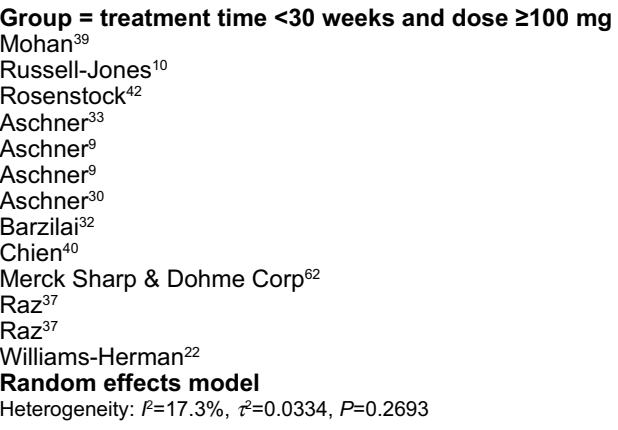 & $\begin{array}{l}0 \\
9 \\
2 \\
10 \\
11 \\
10 \\
19 \\
1 \\
0 \\
3 \\
8 \\
2 \\
8\end{array}$ & $\begin{array}{l}352 \\
163 \\
65 \\
264 \\
238 \\
250 \\
528 \\
102 \\
49 \\
120 \\
205 \\
206 \\
179 \\
\mathbf{2 , 7 2 1}\end{array}$ & $\begin{array}{c}- \\
\vdots \vdots \\
\vdots \vdots \\
\vdots \vdots \\
\vdots \\
\vdots \vdots \\
\square \\
\square \\
\vdots \vdots \\
\square\end{array}$ & $\begin{array}{l}0.0000 \\
0.0552 \\
0.0308 \\
0.0379 \\
0.0462 \\
0.0400 \\
0.0360 \\
0.0098 \\
0.0000 \\
0.0250 \\
0.0390 \\
0.0097 \\
0.0447 \\
\mathbf{0 . 0 3 8 3}\end{array}$ & $\begin{array}{l}0.0000-0.0104 \\
0.0256-0.1022 \\
0.0037-0.1068 \\
0.0183-0.0686 \\
0.0233-0.0812 \\
0.0193-0.0723 \\
0.0218-0.0556 \\
0.0002-0.0534 \\
0.0000-0.0725 \\
0.0052-0.0713 \\
0.0170-0.0754 \\
0.0012-0.0346 \\
0.0195-0.0862 \\
\mathbf{0 . 0 3 0 2 - 0 . 0 4 8 4}\end{array}$ & $\begin{array}{l}0.6 \% \\
4.9 \% \\
2.4 \% \\
5.2 \% \\
5.3 \% \\
5.2 \% \\
6.2 \% \\
1.6 \% \\
0.6 \% \\
3.0 \% \\
4.7 \% \\
2.4 \% \\
4.7 \% \\
\mathbf{4 6 . 9 \%}\end{array}$ \\
\hline $\begin{array}{l}\text { Group }=\text { treatment time }>30 \text { weeks and dose } \geq 100 \mathbf{m g} \\
\text { Schernthaner }{ }^{25} \\
\text { Bergenstal }^{23} \\
\text { Pratley }^{41} \\
\text { Merck Sharp \& Dohme Corp }{ }^{64} \\
\text { Lavalle-Gonzalez }^{61} \\
\text { Bergenstala1 } \\
\text { Goldstein }{ }^{27} \\
\text { Random effects model } \\
\text { Heterogeneity: } P=70.8 \%, \tau^{2}=0.204, P=0.0022\end{array}$ & $\begin{array}{l}26 \\
10 \\
14 \\
1 \\
23 \\
16 \\
5\end{array}$ & $\begin{array}{l}378 \\
184 \\
219 \\
588 \\
366 \\
166 \\
179 \\
\mathbf{2 , 0 8 0}\end{array}$ & \begin{tabular}{r}
$\square$ \\
\hdashline$\vdots$ \\
$\vdots$ \\
$\vdots$ \\
$\vdots$ \\
$\vdots$
\end{tabular} & $\begin{array}{l}0.0688 \\
0.0543 \\
0.0639 \\
0.0017 \\
0.0628 \\
0.0964 \\
0.0279 \\
\mathbf{0 . 0 5 4 1}\end{array}$ & $\begin{array}{l}0.0454-0.0992 \\
0.0264-0.0977 \\
0.0354-0.1049 \\
0.0000-0.0094 \\
0.0402-0.0928 \\
0.0561-0.1518 \\
0.0091-0.0640 \\
\mathbf{0 . 0 3 6 2 - 0 . 0 8 0 1}\end{array}$ & $\begin{array}{l}6.6 \% \\
5.1 \% \\
5.7 \% \\
1.7 \% \\
6.4 \% \\
5.8 \% \\
3.9 \% \\
\mathbf{3 5 . 2} \%\end{array}$ \\
\hline $\begin{array}{l}\text { Group }=\text { treatment time }<30 \text { weeks and dose }<100 \mathrm{mg} \\
\text { Kobayashi }{ }^{43} \\
\text { Merck Sharp \& Dohme Corp }{ }^{63} \\
\text { Chan }^{20} \\
\text { Random effects model } \\
\text { Heterogeneity: } P^{2}=69.5 \%, \tau^{2}=0.6255, P=0.0377\end{array}$ & $\begin{array}{l}4 \\
2 \\
7\end{array}$ & $\begin{array}{l}163 \\
59 \\
65 \\
287\end{array}$ & $\begin{array}{l}7 \vdots \\
\square\end{array}$ & $\begin{array}{r}0.0245 \\
0.0339 \\
0.1077 \\
\mathbf{0 . 0 4 8 1}\end{array}$ & $\begin{array}{l}0.0067-0.0616 \\
0.0041-0.1171 \\
0.0444-0.2094 \\
\mathbf{0 . 0 1 6 8 - 0 . 1 2 9 7}\end{array}$ & $\begin{array}{l}3.5 \% \\
2.4 \% \\
4.3 \% \\
10.2 \%\end{array}$ \\
\hline $\begin{array}{l}\text { Group }=\text { treatment time }>\mathbf{3 0} \text { weeks and dose }<100 \mathbf{~ m g} \\
\text { Ajona Ferreira }{ }^{35} \\
\text { Ajona Ferreira } \\
\text { Random effects model } \\
\text { Heterogeneity: } l^{2}=0 \%, \tau^{2}=0, P=0.4912\end{array}$ & $\begin{array}{c}2 \\
11\end{array}$ & $\begin{array}{l}64 \\
210 \\
\mathbf{2 7 4}\end{array}$ & $\underset{\square}{\square}$ & $\begin{array}{l}0.0312 \\
0.0524 \\
\mathbf{0 . 0 4 8 3}\end{array}$ & $\begin{array}{l}0.0038-0.1084 \\
0.0264-0.0918 \\
\mathbf{0 . 0 2 8 3 - 0 . 0 8 1 5}\end{array}$ & $\begin{array}{l}2.4 \% \\
5.3 \% \\
7.7 \%\end{array}$ \\
\hline $\begin{array}{l}\text { Random effects model } \\
\text { Heterogeneity: } P^{2}=57.6 \%, \tau^{2}=0.1708, P=0.0002\end{array}$ & & 5,362 & $\phi$ & 0.0448 & $0.0359-0.0558$ & $100 \%$ \\
\hline
\end{tabular}

Figure 3 Incidence and risk of diarrhea with sitagliptin use based on subgroups.

Note: aProportion represents diarrhea as a proportion of the different types of reactions to sitagliptin.

Abbreviations: $\mathrm{Cl}$, confidence interval; $\mathrm{W}$, weight.

risk of diarrhea may easily increase in T2DM patients compared with normal people. Another possible explanation for this finding is the underreporting of diarrhea; in fact, diarrhea as an independent adverse event reported in trials is low. In our research, $30.2 \%$ of RCTs were excluded because data on diarrhea were unavailable. Additionally, only 14 RCTs were included in our study to investigate the risk of diarrhea associated with sitagliptin. Thus, the power to investigate the risk is small. Nevertheless, because sitagliptin is increasingly used in routine treatment of T2DM patients and in clinical trials with other agents, endocrinologist and primary care physicians should be aware of the incidence and risk of diarrhea associated with sitagliptin. Furthermore, physicians should monitor and treat this disorder appropriately.

Heterogeneity is a potential confounding factor that can influence the results of all meta-analyses. In the present study, we did not observe a significant heterogeneity in the meta-analysis. However, some limitations did exist. First, the RCTs were performed at various international institutions by different investigators and may have some potential bias in reporting the types of adverse events. In particular, the frequency of diarrhea is underreported in clinical trials independently. Second, the results are from patients at a follow-up time and thus may not be fully reflective of general patients, nor of a more prolonged use. Third, although diarrhea data are prospectively collected in individual studies, there are potentially important differences among the studies, including race, dosage and administration schedules of sitagliptin, duration of the study, and investigators. All of these increase the clinical heterogeneity among included trials. Additionally, our study includes a mixed population of patients treated with sitagliptin-based combination therapy or sitagliptin monotherapy. Therefore, the design of treatment is not the same in all arms, and this might be another source of heterogeneity.

Despite these limitations, the present meta-analysis provides some clinical reference for the treatment of diabetic diarrhea. In the treatment of diabetic diarrhea, it is important 


\begin{tabular}{|c|c|c|c|c|c|c|c|c|}
\hline \multirow[t]{2}{*}{ Study } & \multirow{2}{*}{\multicolumn{2}{|c|}{$\begin{array}{l}\text { Treatment } \\
\text { Events Total }\end{array}$}} & \multicolumn{2}{|c|}{ Control } & \multirow{3}{*}{ Odds ratio } & \multirow[t]{2}{*}{ OR } & \multirow[t]{2}{*}{$95 \% \mathrm{Cl}$} & \multirow[t]{2}{*}{ W (fixed) } \\
\hline & & & Events & Total & & & & \\
\hline $\mathrm{Raz}^{41}$ & 6 & 96 & 5 & 94 & & 1.19 & $0.35-4.03$ & $7.5 \%$ \\
\hline Aschner ${ }^{9}$ & 11 & 238 & 6 & 253 & & 1.99 & $0.73-5.48$ & $8.7 \%$ \\
\hline Aschner ${ }^{9}$ & 10 & 250 & 6 & 253 & & 1.72 & $0.61-4.79$ & $9.0 \%$ \\
\hline 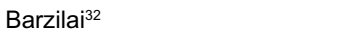 & 1 & 102 & 1 & 104 & & 1.02 & $0.06-16.53$ & $1.5 \%$ \\
\hline Charbonnel $^{19}$ & 12 & 464 & 6 & 237 & & 1.02 & $0.38-2.76$ & $12.2 \%$ \\
\hline $\operatorname{Dobs}^{24}$ & 8 & 170 & 5 & 92 & & 0.86 & $0.27-2.71$ & $9.7 \%$ \\
\hline Goldstein $^{27}$ & 5 & 179 & 7 & 176 & 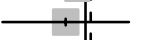 & 0.69 & $0.22-2.23$ & $10.8 \%$ \\
\hline Hermansen ${ }^{38}$ & 3 & 222 & 6 & 219 & 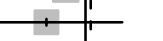 & 0.49 & $0.12-1.97$ & $9.4 \%$ \\
\hline Mohan $^{39}$ & 0 & 352 & 0 & 178 & & & & $0.0 \%$ \\
\hline $\mathrm{Raz}^{37}$ & 8 & 205 & 4 & 110 & & 1.08 & $0.32-3.66$ & $7.9 \%$ \\
\hline $\mathrm{Raz}^{37}$ & 2 & 206 & 4 & 110 & + & 0.26 & $0.05-1.44$ & $8.1 \%$ \\
\hline Rosenstock $^{42}$ & 2 & 65 & 2 & 65 & & 1.00 & $0.14-7.32$ & $3.1 \%$ \\
\hline Rosentock $^{27}$ & 3 & 175 & 2 & 178 & & 1.53 & $0.25-9.30$ & $3.1 \%$ \\
\hline $\operatorname{Scott}^{28}$ & 3 & 94 & 1 & 91 & 11 & 2.97 & $0.30-29.06$ & $1.5 \%$ \\
\hline Yang $^{34}$ & 4 & 191 & 1 & 194 & 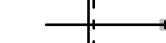 & 4.13 & $0.46-37.28$ & $1.5 \%$ \\
\hline Merck Sharp \& Dohme Corp 62 & 3 & 120 & 4 & 126 & & 0.78 & $0.17-3.57$ & $6.0 \%$ \\
\hline \multirow{2}{*}{\multicolumn{3}{|c|}{$\begin{array}{l}\text { Fixed effect model } \\
\text { Heterogeneity: } P^{2}=0 \%, \tau^{2}=0, P=0.8081\end{array}$}} & 3,129 & 2,480 & & 1.10 & $0.78-1.55$ & $100 \%$ \\
\hline & & & & & \begin{tabular}{cc|c|} 
& & 1 \\
0.5 & 1 & 2
\end{tabular} & & & \\
\hline
\end{tabular}

Figure 4 Odds ratios of diarrhea associated with sitagliptin versus controls. Abbreviations: $\mathrm{OR}$, odds ratio; $\mathrm{Cl}$, confidence interval; $\mathrm{W}$, weight.

to identify the influence of medicine. Metformin, which belongs to the biguanide class of drugs, is the first-line OHA for the treatment of T2DM, and has been shown to reduce the rate of glucose production through reductions in hepatic gluconeogenesis. ${ }^{54,55}$ However, treatment with metformin is generally associated with a high incidence of adverse GI effects, including diarrhea, nausea, and vomiting. ${ }^{56-58}$ Diarrhea is the most commonly reported symptom of adverse GI effects, and metformin can lead to malabsorptive diarrhea ranging from $10 \%$ to $53 \%$ in T2DM patients. ${ }^{59}$ Furthermore, in $5 \%$ of $\mathrm{T} 2 \mathrm{DM}$ cases, diarrhea led to the discontinuation of metformin use.$^{60}$ Our results indicate that sitagliptin did not increase the risk of diabetic diarrhea. The pooled OR of sitagliptin compared with a placebo was 1.10 (95\% CI: $0.78-1.55, P=0.58$; Figure 4). Sitagliptin is not a potential diarrhea-inducing medicine. If diabetic diarrhea occurred, sitagliptin may be a better choice compared with metformin in T2DM patients.

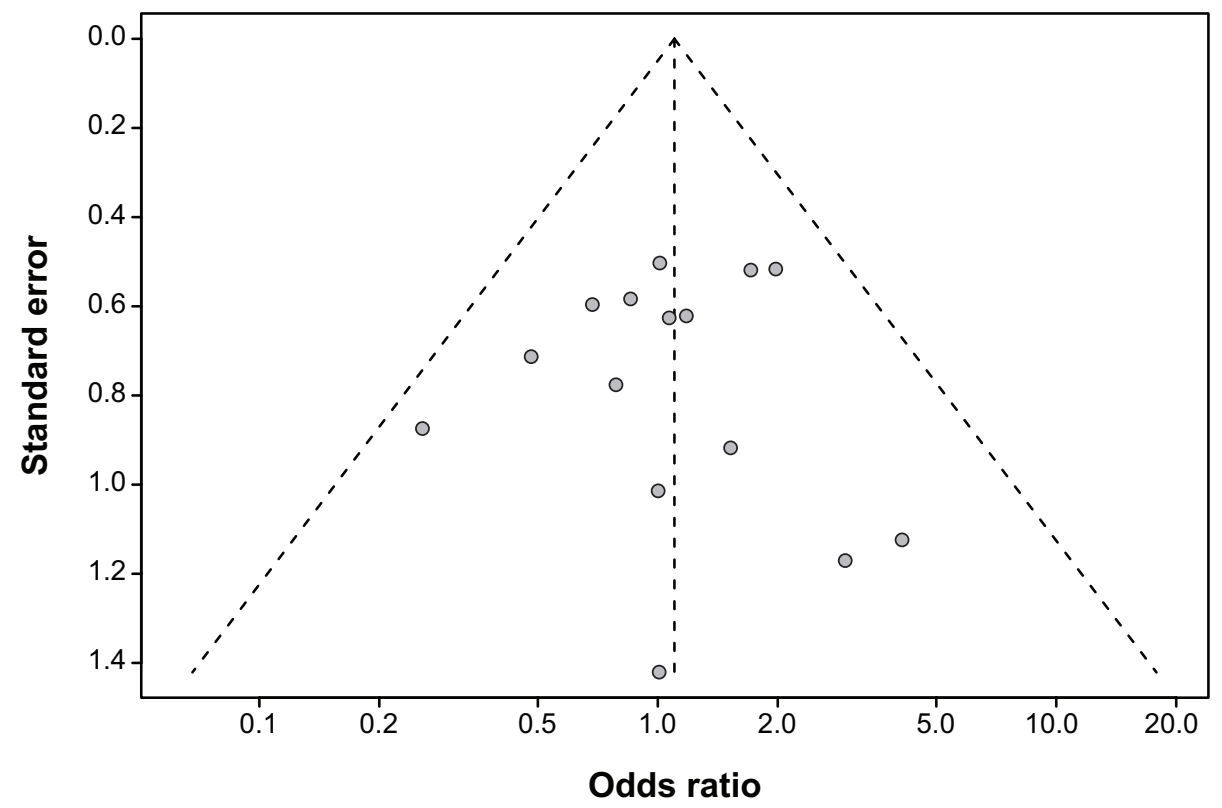

Figure 5 Funnel plot of standard error by odds ratio for diarrhea. 


\section{Conclusion}

In conclusion, our study has shown that there is no difference in diarrhea risk between sitagliptin and controlled therapies. Furthermore, sitagliptin is not a medicine that potentially increases the risk of diabetic diarrhea. Further studies are still recommended to investigate this association.

\section{Acknowledgments}

This work was supported by the Zhejiang TCM KEY research fund projects (number 2013ZZ009), Zhejiang TCM research fund projects (number 2013ZA078), and Zhejiang Provincial Education Department Research Fund Project (number Y201225107).

\section{Disclosure}

There are no financial/commercial conflicts of interest involving any of the authors of this study.

\section{References}

1. Wild S, Roglic G, Green A, Sicree R, King H. Global prevalence of diabetes: estimates for the year 2000 and projections for 2030. Diabetes Care. 2004;27(5):1047-1053.

2. Ren CJ, Zhang Y, Cui WZ, Mu ZM. [Progress in the role of oxidative stress in the pathogenesis of type 2 diabetes]. Sheng Li Xue Bao. 2013;65(6):664-673. Chinese.

3. Bogaert YE, Schrier RW. Into the future: prevention of diabetes. Contrib Nephrol. 2011;170:256-263.

4. Zenari L, Marangoni A. What are the preferred strategies for control of glycaemic variability in patients with type 2 diabetes mellitus? Diabetes Obes Metab. 2013;15 Suppl 2:17-25.

5. McGill JB. Pharmacotherapy in type 2 diabetes: a functional schema for drug classification. Curr Diabetes Rev. 2012;8(4):257-267.

6. Gallwitz B. Sitagliptin: Profile of a novel DPP-4 inhibitor for the treatment of type 2 diabetes. Drugs Today (Barc). 2007;43(1): $13-25$.

7. Omar B, Ahren B. Pleiotropic mechanisms for the glucose-lowering action of DPP-4 inhibitors. Diabetes. 2014;63(7):2196-2202.

8. Gallwitz B. Therapies for the treatment of type 2 diabetes mellitus based on incretin action. Minerva Endocrinol. 2006;31(2):133-147.

9. Aschner P, Kipnes MS, Lunceford JK, et al. Effect of the dipeptidyl peptidase-4 inhibitor sitagliptin as monotherapy on glycemic control in patients with type 2 diabetes. Diabetes Care. 2006;29(12): 2632-2637.

10. Russell-Jones D, Cuddihy RM, Hanefeld M, et al. Efficacy and safety of exenatide once weekly versus metformin, pioglitazone, and sitagliptin used as monotherapy in drug-naive patients with type 2 diabetes (DURATION-4): a 26-week double-blind study. Diabetes Care. 2012;35(2):252-258.

11. Begg CB, Mazumdar M. Operating characteristics of a rank correlation test for publication bias. Biometrics. 1994;50(4):1088-1101.

12. American Diabetes Association. Standards of medical care in diabetes2014. Diabetes Care. 2014;37(Suppl 1):S14-S80.

13. World Health Organization. Definition, Diagnosis, and Classification of Diabetes Mellitus and its Complications: report of a WHO consultation. Geneva: World Health Organization; 1999. Available from: http:// whqlibdoc.who.int/hq/1999/who_ncd_ncs_99.2.pdf. Accessed October 3, 2014.

14. Jadad AR, Moore RA, Carroll D, et al. Assessing the quality of reports of randomized clinical trials: is blinding necessary? Control Clin Trials. 1996;17(1):1-12.
15. Sweeting MJ, Sutton AJ, Lambert PC. What to add to nothing? Use and avoidance of continuity corrections in meta-analysis of sparse data. Stat Med. 2004;23(9):1351-1375.

16. Zintzaras E, Ioannidis JP. Heterogeneity testing in meta-analysis of genome searches. Genet Epidemiol. 2005;28(2):123-137.

17. Egger M, Davey Smith G, Schneider M, Minder C. Bias in metaanalysis detected by a simple, graphical test. BMJ. 1997;315(7109): 629-634.

18. Maindonald J, Braun WJ. Data Analysis and Graphics Using R: An Example-Based Approach. 3rd ed. New York: Cambridge University Press; 2010.

19. Charbonnel B, Karasik A, Liu J, Wu M, Meininger G; Sitagliptin Study 020 Group. Efficacy and safety of the dipeptidyl peptidase-4 inhibitor sitagliptin added to ongoing metformin therapy in patients with type 2 diabetes inadequately controlled with metformin alone. Diabetes Care. 2006;29(12):2638-2643.

20. Chan JCN, Scott R, Arjona Ferreira JC, et al. Safety and efficacy of sitagliptin in patients with type 2 diabetes and chronic renal insufficiency. Diabetes Obes Metab. 2008;10(7):545-555.

21. Williams-Herman D, Johnson J, Teng R, et al. Efficacy and safety of initial combination therapy with sitagliptin and metformin in patients with type 2 diabetes: a 54-week study. Curr Med Res Opin. 2009;25(3):569-583.

22. Williams-Herman D, Johnson J, Teng R, et al. Efficacy and safety of sitagliptin and metformin as initial combination therapy and as monotherapy over 2 years in patients with type 2 diabetes. Diabetes Obes Metab. 2010;12(5):442-451.

23. Bergenstal RM, Forti A, Chiasson J-L, Woloschak M, Boldrin M, Balena R. Efficacy and safety of taspoglutide versus sitagliptin for type 2 diabetes mellitus (T-emerge 4 trial). Diabetes Ther. 2012; 3(1):13.

24. Dobs AS, Goldstein BJ, Aschner P, et al. Efficacy and safety of sitagliptin added to ongoing metformin and rosiglitazone combination therapy in a randomized placebo-controlled 54-week trial in patients with type 2 diabetes. J Diabetes. 2013;5(1):68-79.

25. Schernthaner G, Gross JL, Rosenstock J, et al. Canagliflozin compared with sitagliptin for patients with type 2 diabetes who do not have adequate glycemic control with metformin plus sulfonylurea: a 52-week randomized trial. Diabetes Care. 2013;36(9):2508-2515.

26. Rosenstock J, Brazg R, Andryuk PJ, Lu K, Stein P; Sitagliptin Study 019 Group. Efficacy and safety of the dipeptidyl peptidase-4 inhibitor sitagliptin added to ongoing pioglitazone therapy in patients with type 2 diabetes: a 24-week, multicenter, randomized, double-blind, placebo-controlled, parallel-group study. Clin Ther. 2006;28(10): $1556-1568$.

27. Goldstein BJ, Feinglos MN, Lunceford JK, Johnson J, WilliamsHerman DE; Sitagliptin 036 Study Group. Effect of initial combination therapy with sitagliptin, a dipeptidyl peptidase-4 inhibitor, and metformin on glycemic control in patients with type 2 diabetes. Diabetes Care. 2007; 30(8):1979-1987.

28. Scott R, Wu M, Sanchez M, Stein P. Efficacy and tolerability of the dipeptidyl peptidase-4 inhibitor sitagliptin as monotherapy over 12 weeks in patients with type 2 diabetes. Int J Clin Pract. 2007;61(1):171-180.

29. Raz I, Chen Y, Wu M, et al. Efficacy and safety of sitagliptin added to ongoing metformin therapy in patients with type 2 diabetes. Curr Med Res Opin. 2008;24(2):537-550.

30. Aschner P, Katzeff HL, Guo H, et al. Efficacy and safety of monotherapy of sitagliptin compared with metformin in patients with type 2 diabetes. Diabetes Obes Metab. 2010;12(3):252-261.

31. Bergenstal RM, Wysham C, Macconell L, et al. Efficacy and safety of exenatide once weekly versus sitagliptin or pioglitazone as an adjunct to metformin for treatment of type 2 diabetes (DURATION-2): a randomised trial. Lancet. 2010;376(9739):431-439.

32. Barzilai N, Guo H, Mahoney EM, et al. Efficacy and tolerability of sitagliptin monotherapy in elderly patients with type 2 diabetes: a randomized, double-blind, placebo-controlled trial. Curr Med Res Opin. 2011;27(5):1049-1058. 
33. Aschner P, Chan J, Owens DR, et al. Insulin glargine versus sitagliptin in insulin-naive patients with type 2 diabetes mellitus uncontrolled on metformin (EASIE): a multicentre, randomised open-label trial. Lancet. 2012;379(9833):2262-2269.

34. Yang W, Guan Y, Shentu Y, et al. The addition of sitagliptin to ongoing metformin therapy significantly improves glycemic control in Chinese patients with type 2 diabetes. J Diabetes. 2012;4(3):227-237.

35. Arjona Ferreira JC, Corry D, Mogensen CE, et al. Efficacy and safety of sitagliptin in patients with type 2 diabetes and ESRD receiving dialysis: a 54-week randomized trial. Am J Kidney Dis. 2013;61(4): 579-587.

36. Arjona Ferreira JC, Marre M, Barzilai N, et al. Efficacy and safety of sitagliptin versus glipizide in patients with type 2 diabetes and moderate-to-severe chronic renal insufficiency. Diabetes Care. 2013;36(5):1067-1073.

37. Raz I, Hanefeld M, Xu L, et al. Efficacy and safety of the dipeptidyl peptidase-4 inhibitor sitagliptin as monotherapy in patients with type 2 diabetes mellitus. Diabetologia. 2006;49(11):2564-2571.

38. Hermansen K, Kipnes M, Luo E, et al. Efficacy and safety of the dipeptidyl peptidase- 4 inhibitor, sitagliptin, in patients with type 2 diabetes mellitus inadequately controlled on glimepiride alone or on glimepiride and metformin. Diabetes Obes Metab. 2007;9(5):733-745.

39. Mohan V, Yang W, Son H-Y, et al. Efficacy and safety of sitagliptin in the treatment of patients with type 2 diabetes in China, India, and Korea. Diabetes Res Clin Pract. 2009;83(1):106-116.

40. Chien M-N, Lee C-C, Chen W-C, Liu S-C, Leung C-H, Wang C-H. Effect of sitagliptin as add-on therapy in elderly type 2 diabetes patients with inadequate glycemic control in Taiwan. Int J Gerontol. 2011;5(2):103-106.

41. Pratley R, Nauck M, Bailey T, et al. One year of liraglutide treatment offers sustained and more effective glycaemic control and weight reduction compared with sitagliptin, both in combination with metformin, in patients with type 2 diabetes: a randomised, parallel-group, open-label trial. Int J Clin Pract. 2011;65(4):397-407.

42. Rosenstock J, Aggarwal N, Polidori D, et al. Dose-ranging effects of canagliflozin, a sodium-glucose cotransporter 2 inhibitor, as add-on to metformin in subjects with type 2 diabetes. Diabetes Care. 2012;35(6):1232-1238.

43. Kobayashi K, Yokoh H, Sato Y, et al. Efficacy and safety of the dipeptidyl peptidase-4 inhibitor sitagliptin compared with $\alpha$-glucosidase inhibitor in Japanese patients with type 2 diabetes inadequately controlled on sulfonylurea alone (SUCCESS-2): a multicenter, randomized, open-label, non-inferiority trial. Diabetes Obes Metab. 2014;16(8):761-765.

44. Moher D, Liberati A, Tetzlaff J, Altman DG. Preferred reporting items for systematic reviews and meta-analyses: the PRISMA statement. Int J Surg. 2010;8(5):336-341.

45. Scott R, Loeys T, Davies MJ, et al. Efficacy and safety of sitagliptin when added to ongoing metformin therapy in patients with type 2 diabetes. Diabetes Obes Metab. 2008;10(10):959-969.

46. Wu D, Li L, Liu C. Efficacy and safety of dipeptidyl peptidase-4 inhibitors and metformin as initial combination therapy and as monotherapy in patients with type 2 diabetes mellitus: a meta-analysis. Diabetes Obes Metab. 2014;16(1):30-37.

47. Argyrakopoulou G, Doupis J. DPP4 inhibitors: from sitagliptin monotherapy to the new alogliptin-pioglitazone combination therapy. Adv Ther. 2009;26(3):272-280.
48. Hanefeld M, Herman GA, Wu M, et al. Once-daily sitagliptin, a dipeptidyl peptidase- 4 inhibitor, for the treatment of patients with type 2 diabetes. Curr Med Res Opin. 2007;23(6):1329-1339.

49. Scott R, Wu M, Sanchez M, Stein P. Efficacy and tolerability of the dipeptidyl peptidase-4 inhibitor sitagliptin as monotherapy over 12 weeks in patients with type 2 diabetes. Int J Clin Pract. 2007;61(1):171-180.

50. Oh JH, Choi MG, Kang MI, et al. The prevalence of gastrointestinal symptoms in patients with non-insulin dependent diabetes mellitus. Korean J Intern Med. 2009;24(4):309-317.

51. Bytzer P, Talley NJ, Leemon M, Young LJ, Jones MP, Horowitz M. Prevalence of gastrointestinal symptoms associated with diabetes mellitus: a population-based survey of 15,000 adults. Arch Intern Med. 2001;161(16):1989-1996

52. Nakamura T, Suda T, Kon M. Pathophysiology and treatment of diabetic diarrhea. J Smooth Muscle Res. 1996;32(2):27-42.

53. Mei Q, Mundinger TO, Lernmark A, Taborsky GJ. Early, selective, and marked loss of sympathetic nerves from the islets of biobreeder diabetic rats. Diabetes. 2002;51(10):2997-3002.

54. Johnson AB, Webster JM, Sum CF, et al. The impact of metformin therapy on hepatic glucose production and skeletal muscle glycogen synthase activity in overweight type II diabetic patients. Metabolism. 1993;42(9):1217-1222.

55. Perriello G, Misericordia P, Volpi E, et al. Acute antihyperglycemic mechanisms of metformin in NIDDM. Evidence for suppression of lipid oxidation and hepatic glucose production. Diabetes. 1994;43(7):920-928.

56. Jabbour S, Ziring B. Advantages of extended-release metformin in patients with type 2 diabetes mellitus. Postgrad Med. 2011;123(1):15-23.

57. Zolk O. Disposition of metformin: variability due to polymorphisms of organic cation transporters. Ann Med. 2012;44(2):119-129.

58. Padwal RS, Gabr RQ, Sharma AM, et al. Effect of gastric bypass surgery on the absorption and bioavailability of metformin. Diabetes Care. 2011;34(6):1295-1300.

59. Gould M, Sellin JH. Diabetic diarrhea. Curr Gastroenterol Rep. 2009;11(5):354-359.

60. Bouchoucha M, Uzzan B, Cohen R. Metformin and digestive disorders. Diabetes Metab. 2011;37(2):90-96.

61. Lavalle-Gonzalez FJ, Januszewicz A, Davidson J, et al. Efficacy and safety of canagliflozin compared with placebo and sitagliptin in patients with type 2 diabetes on background metformin monotherapy: a randomised trial. Diabetologia. 2013;56(12):2582-2592.

62. Merck Sharp \& Dohme Corp. Safety and Efficacy of Co-Administration of Sitagliptin and Metformin in China (MK-0431-121). Available from: http://www.clinicaltrials.gov/ct2/show/NCT01076088?term=NCT0107 6088\&rank=1. NLM identifier: NCT 01076088. Accessed October 23, 2014.

63. Merck Sharp \& Dohme Corp. A Study of Sitagliptin in Patients With Type 2 Diabetes Mellitus Who Have Inadequate Glycemic Control on Diet/Exercise Therapy (0431-054). Available from: http://www. clinicaltrials.gov/ct2/show/NCT00411554?term=00411554\&rank=1. NLM identifier: NCT 00411554. Accessed October 23, 2014.

64. Merck Sharp \& Dohme Corp. An Investigational Drug Study in Patients With Type 2 Diabetes Mellitus (0431-024). Available from: http://www. clinicaltrials.gov/ct2/show/NCT00094770?term=NCT00094770\&rank =1. NLM identifier: NCT 00094770. Accessed October 23, 2014. 


\section{Supplementary materials}

1. Diabetes [title/abstract]

2. Diabetes mellitus [title/abstract]

3. Type 2 diabetes [title/abstract]

4. Noninsulin-dependent diabetes mellitus [title/abstract]

5. Diabetes mellitus [exp]

6. Noninsulin-dependent diabetes mellitus [exp]

7. Sitagliptin [title/abstract]

8. Randomized controlled trials [title/abstract]

9. Clinical trials [title/abstract]

10. Controlled clinical trials [title/abstract]

11. Controlled clinical trial [exp]

12. Controlled clinical trial (topic) [exp]

13. Clinical trial [exp]

14. Clinical trial (topic) [exp]

15. Randomized controlled trial [exp]

16. Randomized controlled trial (topic) [exp]

17. 1 OR 2 OR 3 OR 4 OR 5 OR 6

18. 8 OR 9 OR 10 OR 11 OR 12 OR 13 OR 14 OR 15 OR 16

20.7 AND 17 AND 18

Figure SI Embase search strategy.

Abbreviation: exp, extensive search.

1. Diabetes [title/abstract]

2. Diabetes mellitus [title/abstract]

3. Type 2 diabetes [title/abstract]

4. Noninsulin-dependent diabetes mellitus [title/abstract]

5. Diabetes mellitus, type 2 [Medical Subject Headings, $\mathrm{MeSH}]$

Table SI PRISMA 2009 checklist

\begin{tabular}{|c|c|c|c|}
\hline Section/topic & No & Checklist & $\begin{array}{l}\text { Reported } \\
\text { on page no }\end{array}$ \\
\hline \multicolumn{4}{|l|}{ Title } \\
\hline Title & $\mathrm{I}$ & Identify the report as a systematic review, meta-analysis, or both & I \\
\hline \multicolumn{4}{|l|}{ Abstract } \\
\hline $\begin{array}{l}\text { Structured } \\
\text { summary }\end{array}$ & 2 & $\begin{array}{l}\text { Provide a structured summary including, as applicable: background, objectives, data sources, } \\
\text { study eligibility criteria, participants, interventions, study appraisal and synthesis methods, } \\
\text { results, limitations, conclusions and implications of key findings, systematic review registration } \\
\text { number }\end{array}$ & $\mathrm{I}$ \\
\hline \multicolumn{4}{|c|}{ (1) } \\
\hline Rationale & 3 & Describe the rationale for the review in the context of what is already known & 1 \\
\hline Objectives & 4 & $\begin{array}{l}\text { Provide an explicit statement of questions being addressed with reference to participants, } \\
\text { interventions, comparisons, outcomes, and study design (PICOS) }\end{array}$ & I \\
\hline \multicolumn{4}{|c|}{ ( } \\
\hline $\begin{array}{l}\text { Protocol and } \\
\text { registration }\end{array}$ & 5 & $\begin{array}{l}\text { Indicate if a review protocol exists, if and where it can be accessed (eg, web address), and, if } \\
\text { available, provide registration information including registration number }\end{array}$ & 2 \\
\hline Eligibility criteria & 6 & $\begin{array}{l}\text { Specify study characteristics (eg, PICOS, length of follow-up) and report characteristics } \\
\text { (eg, years considered, language, publication status) used as criteria for eligibility, giving rationale }\end{array}$ & 2 \\
\hline $\begin{array}{l}\text { Information } \\
\text { sources }\end{array}$ & 7 & $\begin{array}{l}\text { Describe all information sources (eg, databases with dates of coverage, contact with study } \\
\text { authors to identify additional studies) in the search and date last searched }\end{array}$ & 2 \\
\hline Search & 8 & $\begin{array}{l}\text { Present full electronic search strategy for at least one database, including any limits used, such } \\
\text { that it could be repeated }\end{array}$ & 2 \\
\hline
\end{tabular}

Figure S3 Cochrane Library search strategy.

Abbreviations: ab, abstract; kw, keyword; ti, title.
1. Sitagliptin: ti, ab, kw

2. Diabetes: ti, ab, kw

3. Diabetes mellitus: ti, ab, kw

4. Type 2 diabetes: ti, ab, $\mathrm{kw}$

5. Noninsulin-dependent diabetes mellitus: ti, ab, kw

6. MeSH descriptor: [diabetes mellitus]

7. MeSH descriptor: [diabetes mellitus, type 2]

8. 2 OR 3 OR 4 OR 5 OR 6 OR 7

9. 1 AND 8

10. Select trials result of 9
6. Diabetes mellitus [MeSH]

8. Sitagliptin [supplementary concept]

9. Randomized controlled trials [title/abstract]

e/abstract]
12. Clinical trials as topic [MeSH]
13. Controlled clinical trials as topic $[\mathrm{MeSH}]$
14 . Randomized controlled trials as topic $[\mathrm{MeSt}$
14. Randomized controlled trials as topic [MeSH]
17. Clinical trials, Phase IV as topic [MeSH]
20.9 OR 10 OR 11 OR 12 OR 13 OR 14 OR 15 OR 16 OR 17 21. 18 AND 19 AND 20
11. Controlled clinical trials [title/abstract]
15. Clinical trials, Phase II as topic [MeSH]
19.7 OR 8

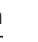


Table SI (Continued)

\begin{tabular}{|c|c|c|c|}
\hline Section/topic & No & Checklist & $\begin{array}{l}\text { Reported } \\
\text { on page no }\end{array}$ \\
\hline Study selection & 9 & $\begin{array}{l}\text { State the process for selecting studies (ie, screening, eligibility, included in systematic review, } \\
\text { and, if applicable, included in the meta-analysis) }\end{array}$ & 2 \\
\hline $\begin{array}{l}\text { Data collection } \\
\text { process }\end{array}$ & 10 & $\begin{array}{l}\text { Describe method of data extraction from reports (eg, piloted forms, independently, in } \\
\text { duplicate) and any processes for obtaining and confirming data from investigators }\end{array}$ & 2 \\
\hline Data items & II & $\begin{array}{l}\text { List and define all variables for which data were sought (eg, PICOS, funding sources) and any } \\
\text { assumptions and simplifications made }\end{array}$ & 2 \\
\hline $\begin{array}{l}\text { Risk of bias } \\
\text { in individual } \\
\text { studies }\end{array}$ & 12 & $\begin{array}{l}\text { Describe methods used for assessing risk of bias of individual studies (including specification of } \\
\text { whether this was done at the study or outcome level) and how this information is to be used in } \\
\text { any data synthesis }\end{array}$ & 2 \\
\hline $\begin{array}{l}\text { Summary } \\
\text { measures }\end{array}$ & 13 & State the principal summary measures (eg, risk ratio, difference in means) & 2 \\
\hline Search & 8 & $\begin{array}{l}\text { Present full electronic search strategy for at least one database, including any limits used, such } \\
\text { that it could be repeated }\end{array}$ & 2 \\
\hline $\begin{array}{l}\text { Risk of bias } \\
\text { across studies }\end{array}$ & 15 & $\begin{array}{l}\text { Specify any assessment of risk of bias that may affect the cumulative evidence (eg, publication } \\
\text { bias, selective reporting within studies) }\end{array}$ & 2 \\
\hline $\begin{array}{l}\text { Additional } \\
\text { analyses } \\
\text { Results }\end{array}$ & 16 & $\begin{array}{l}\text { Describe methods of additional analyses (eg, sensitivity or subgroup analyses, meta-regression), } \\
\text { if done, indicating which were prespecified }\end{array}$ & 2 \\
\hline Study selection & 17 & $\begin{array}{l}\text { Give numbers of studies screened, assessed for eligibility, and included in the review, with } \\
\text { reasons for exclusions at each stage, ideally with a flow diagram }\end{array}$ & 3 \\
\hline $\begin{array}{l}\text { Study } \\
\text { characteristics }\end{array}$ & 18 & $\begin{array}{l}\text { For each study, present characteristics for which data were extracted (eg, study size, PICOS, } \\
\text { follow-up period) and provide the citations }\end{array}$ & 3 \\
\hline $\begin{array}{l}\text { Risk of bias } \\
\text { within studies }\end{array}$ & 19 & $\begin{array}{l}\text { Present data on risk of bias of each study and, if available, any outcome level assessment } \\
\text { (see item 12) }\end{array}$ & 3 \\
\hline $\begin{array}{l}\text { Results of } \\
\text { individual } \\
\text { studies }\end{array}$ & 20 & $\begin{array}{l}\text { For all outcomes considered (benefits or harms), present, for each study: (a) simple summary } \\
\text { data for each intervention group and (b) effect estimates and confidence intervals, ideally with } \\
\text { a forest plot }\end{array}$ & 3 \\
\hline $\begin{array}{l}\text { Synthesis of } \\
\text { results }\end{array}$ & 21 & $\begin{array}{l}\text { Present results of each meta-analysis done, including confidence intervals and measures of } \\
\text { consistency }\end{array}$ & 3 \\
\hline $\begin{array}{l}\text { Risk of bias } \\
\text { across studies }\end{array}$ & 22 & Present results of any assessment of risk of bias across studies (see item I5) & 4 \\
\hline $\begin{array}{l}\text { Additional } \\
\text { analysis } \\
\text { Discussion }\end{array}$ & 23 & $\begin{array}{l}\text { Give results of additional analyses, if done (eg, sensitivity or subgroup analyses, meta-regression } \\
\text { [see item 16]) }\end{array}$ & 3 \\
\hline $\begin{array}{l}\text { Summary } \\
\text { of evidence }\end{array}$ & 24 & $\begin{array}{l}\text { Summarize the main findings including the strength of evidence for each main outcome; } \\
\text { consider their relevance to key groups (eg, health care providers, users, and policymakers) }\end{array}$ & 4 \\
\hline Limitations & 25 & $\begin{array}{l}\text { Discuss limitations at study and outcome level (eg, risk of bias) and at review level } \\
\text { (eg, incomplete retrieval of identified research, reporting bias) }\end{array}$ & $4-5$ \\
\hline Conclusions & 26 & $\begin{array}{l}\text { Provide a general interpretation of the results in the context of other evidence, and } \\
\text { implications for future research }\end{array}$ & 5 \\
\hline \multicolumn{4}{|c|}{ P } \\
\hline Funding & 27 & $\begin{array}{l}\text { Describe sources of funding for the systematic review and other support (eg, supply of data); } \\
\text { role of funders for the systematic review }\end{array}$ & 5 \\
\hline
\end{tabular}

Reproduced from Moher D, Liberati A, Tetzlaff J, et al. Preferred reporting items for systematic reviews and meta-analyses: the PRISMA statement. Plos Med. 2009;6(7): el000097.'

Abbreviations: No, number; PICOS, patient, intervention, comparison, outcome and study; PRISMA, preferred reporting items for systematic reviews and meta-analyses.

\section{Reference}

1. Moher D, Liberati A, Tetzlaff J, Altman DG; the PRISMA Group.

Preferred reporting items for systematic reviews and meta-analyses: the PRISMA statement. Plos Med. 2009;6(7):e1000097.

\section{Publish your work in this journal}

Drug Design, Development and Therapy is an international, peerreviewed open-access journal that spans the spectrum of drug design and development through to clinical applications. Clinical outcomes, patient safety, and programs for the development and effective, safe, and sustained use of medicines are a feature of the journal, which has also been accepted for indexing on PubMed Central. The manuscript management system is completely online and includes a very quick and fair peer-review system, which is all easy to use. Visit http://www.dovepress.com/testimonials.php to read real quotes from published authors. 